\title{
Hakikat Pendidik dalam Perspektif Falsafah Pendidikan Islami
}

\author{
Maisyaroh \\ Pascasarjana Universitas Islam Negeri Sumatera Utara Medan, Indonesia \\ Jalan Willem Iskandar Pasar V Medan Estate, Medan, Sumatera Utara, 20371 \\ Email: ara.isyraqi@gmail.com
}

\begin{abstract}
This article examines the perspective of Islamic education philosophy about the nature of educators. This study is important because the concept of education in the Islamic world is influenced by the secular Western worldview. In fact, Muslims have a unique worldview which is sourced from the Qur'an, hadith and ijtihad of the scholars. This study is the result of library research where data is obtained through document study activities that are analyzed by content analysis. This study proposes that in the view of Islam, the nature of educators is Allah, the Prophets and scholars. Therefore, Muslim educators are obliged to emulate their qualities and continue their duties as idealized educators in the Islamic view.
\end{abstract}

Keywords: Educational Philosophy, Educators, Murabbi, Mu'allim, Mu'addib

Abstrak: Artikel ini mengkaji perspektif falsafah pendidikan Islami tentang hakikat pendidik. Studi ini penting dilakukan mengingat konsep pendidikan di dunia Islam dipengaruhi oleh pandangan dunia Barat yang sekular. Padahal, kaum Muslim memiliki pandangan dunia yang khas yang bersumber dari al-Qur'an, hadis dan ijtihad para ulama. Studi ini merupakan hasil riset kepustakaan dimana data diperoleh melalui kegiatan studi dokumen yang dianalisis dengan analisis isi. Studi ini mengajukan temuan bahwa dalam pandangan Islam, hakikat pendidik adalah Allah Swt., para Nabi dan Rasul dan para ulama. Karena itu, para pendidik Muslim wajib meneladani sifat-sifat mereka dan meneruskan tugas-tugas mereka sebagai pendidik terideal dalam pandangan Islam.

Kata Kunci: Falsafah Pendidikan, Pendidik, Murabbi, Mu'allim, Mu'addib 


\section{PENDAHULUAN}

Berbicara pendidikan tidak bisa melepaskan diri dari pembahasan tentang berbagai komponan pendidikan. Di antara komponen pendidikan adalah pendidik, peserta didik, tujuan, kurikulum, metode, evaluasi dan lembaga-lembaga pendidikan. Para ahli telah membahas persoalan-persoalan komponen pendidikan tersebut dengan pendekatan masing-masing dan didasarkan pada ideologi masing-masing. Menurut penulis, perbedaan ideologi akan menghasilkan perbedaan konsep dasar pendidikan.

Dalam makalah ini, penulis akan membahas hakikat pendidik dalam perspektif falsafah pendidikan Islami. Mengkaji konsep pendidik dengan sudut pandangan falsafah pendidikan Islami sangat penting agar kaum Muslim memiliki konsep pendidikan yang sesuai dengan ajaran Islam. Hal ini menarik dan penting, sebab konsep pendidikan di dunia Muslim dipengaruhi oleh pandangan dunia Barat yang sekuler. Sebab itulah, penulis akan mengkaji hakikat pendidik menurut falsafah pendidikan Islami demi menghadirkan pandangan Islam tentang hakikat pendidik.

Studi ini merupakan studi kepustakaan. Data diperoleh melalui kegiatan telaah dokumen dengan metode analisis isi. Sedapat mungkin penulis merujuk sumber primer dalam kajian ilmu-ilmu keislaman. Memang, banyak studi telah dilakukan terkait hakikat pendidik dalam Islam, tetapi penulis mengkajinya dari sudut pandang normatif dan filosofis dengan merujuk kepada alQur'an, hadis dan pendapat para ulama dalam tradisi intelektual Islam.

Dapat dikatakan bahwa studi ini menindaklanjuti studi yang dilakukan oleh Al Rasyidin (2018) dan beberapa peneliti yang merupakan kontributor dalam buku Falsafah Pendidikan Islami yang diedit oleh Asrul dan Ja'far (2016).
Al Rasyidin meneliti konsep falsafah pendidikan dalam perspektif Islam dimana ia lebih menekankan pada dimensi normatif. Kajian-kajian dalam buku Falsafah Pendidikan Islami lebih bervariatif dengan melihat kajian filsafat pendidikan Islam dalam tradisi kewahyuan, pemikiran dan sejarah Islam, misalnya dikaji falsafah pendidikan Muhammadiyah, Nahdlatul Ulama dan Al Jam'iyatul Washliyah (Ja'far, 2016: 2017). Studi yang penulis lakukan diharapkan bisa memperkaya kajian-kajian dalam studi falsafah pendidikan Islami.

\section{KONSEP TEORI \\ Filsafat Pendidikan Islam}

Penulis melihat bahwa term "filsafat pendidikan Islam" terdiri atas dua istilah utama, filsafat atau falsafat dan pendidikan Islam. Kata filsafat berasal dari bahasa Yunani, philo dan sophos atau sophia. Kata philo bermakna cinta, sedangkan kata sophos atau sophia berarti kebijaksanaan (Netton, 1997: 78-79). Karenanya, secara etimologi, filsafat berarti cinta terhadap kebijaksanaan atau kearifan. Dalam bahasa Arab, menurut ahli, kata filsafat merupakan sinonim dari kata al-hikmah (Huges, 2002: 175). AlQur'an menyebut kata hikmah 20 kali.Bagi ahli filsafat, adanya kata hikmah dalam AlQur'an menunjukkan bahwa kajian filsafat dibenarkan oleh Islam sejauh tidak bertentangan dengan prinsip pokok Islam. Istilah kedua adalah pendidikan Islam. Artinya, pendidikan yang berdasarkan sumber pokok ajaran Islam, yaitu al-Qur'an dan hadis. Menurut John Dewey (1944: 1-4), pendidikan adalah "proses memfasilitasi pembelajaran guna menyebarkan pengetahuan, keterampilan, nilai-nilai, kepercayaan dan kebiasaan, dimana pendidik membimbing peserta didik agar dapat membelajarkan diri mereka sendiri." Para ahli menyebutkan bahwa pendidikan berfungsi sebagai "media penanaman pengetahuan, sikap, 
dan keterampilan" (Gibbs and Blakely: 2000 47). Dalam kajian pendidikan, ada beberapa permasalahan yang dikaji, menurut Dja'far Siddik, antara lain pendidik, peserta didik, tujuan, metode, kurikulum, evaluasi, supervisi, dan institusi pendidikan (Siddik: 2010). Inilah yang merupakan masalah-masalah pokok dalam kajian pendidikan. Dalam konteks pendidikan Islam, konsep pendidikan harus berdasarkan ajaran Islam yang bersumber dari al-Qur'an, hadis dan tradisi para ulama (ijtih $\dot{\bar{a}}$ ). Dengan demikian, dari aspek sumber, konsepkonsep pendidikan Islam bersumber dari ajaran Islam yang bermuara pada AlQur'an, hadis dan ijtihad para ulama (Syafaruddin, et al., 2014: 30-31).

Kedua istilah tersebut membentuk filsafat pendidikan Islam atau falsafah pendidikan Islami. Para ahli sudah menjelaskan makna filsafat pendidikan Islam. Dalam kesempatan ini, penulis akan menyampaikan beberapa pendapat para pakar tentang makna filsafat pendidikan Islam. Al-Syaibani (1979: 399) mengatakan bahwa filsafat pendidikan "pelaksanaan pandangan dan kaedah falsafah dalam bidang pendidikan." Pandangan ini didukung oleh Sutan Zanti Arbi (1988: 8) yang mengatakan bahwa filsafat pendidikan adalah "aplikasi dari filsafat terhadap pengkajian persoalanpersoalan pendidikan." Imam Barnadib (1984: 14) mengatakan filsafat pendidikan adalah "jawaban dari pertanyaan-pertanyaan dalam lapangan pendidikan." M. Napitupulu menyebut bahwa filsafat pendidikan adalah "filsafat diaplikasikan terhadap ilmu pendidikan."

Dari empat pendapat ahli di atas, penulis menarik kesimpulan bahwa filsafat pendidikan (Islam) adalah disiplin ilmu yang hendak menerapkan falsafah (ajaran) Islam yang bersumber dari alQur'an, hadis dan pendapat para ulama dalam dunia pendidikan.
Penulis cenderung kepada pendapat al-Syaibani, sehingga makna filsafat pendidikan Islam adalah implementasi prinsip dan kaedah ajaran Islam dalam bidang pendidikan, dalam arti bahwa masalah-masalah pendidikan harus berasal dari prinsip dan kaedah ajaran Islam. Filsafat pendidikan merupakan cabang dari filsafat (Syafaruddin dan $\mathrm{Al}$ Rasyidin, 2001: 37). Menurut al-Syaibani (1979: 33-36), filsafat pendidikan Islami berfungsi sebagai, salah satunya, membantu para perancang dan pelaksana pendidikan dalam suatu negara untuk membentuk pemikiran yang sehat terkait pendidikan. Dengan demikian, kajian filsafat pendidikan Islam penting diketahui oleh para perancang dan pelaksana pendidikan, agar mereka dapat menemukan konsep pendidikan yang relevan dengan ajaran Islam, karena substansi filsafat pendidikan Islam adalah mengimplementasikan falsafah ajaran Islam dalam dunia pendidikan kaum Muslim, atau menjadikan ajaran Islam sebagai dasar perumusan berbagai teori pendidikan (Asrul dan Ja'far, 2016: xiii).

\section{MOTODE PENELITIAN}

Tulisan ini menggunakan metode penelitian kepustakaan (library research) yaitu penelitian yang mengandalkan bahan-bahan kepustakaan sebagai sumber informasi untuk menjawab permasalahan tentang hakikat pendidik dalam perspektif falsafah pendidikan Islami. Tahapan penelitian yang dilakukan adalah mengumpulkan bahan-bahan yang relevan, kemudian bahan-bahan tersebut akan dibaca, dikaji, dicatat dan kemudian dimanfaatkan sebaik mungkin. Setelah semua tahapan tuntas barulah data dianalisis dengan cara analisis isi sehingga dapat ditarik kesimpulan terkait pendidik dalam perspektif falsafah islami. 
HASIL DAN PEMBAHASAN

\section{Hakikat Pendidik Dalam Filsafat Pendidikan Islami}

Dalam kesempatan kali ini, penulis akan membahas empat permasalahan terkait hakikat pendidik, yaitu terminologi pendidik, hakikat pendidik, kepribadian pendidik dan tugas pendidik. Untuk membahas empat masalah tersebut, penulis akan mengulasnya menurut kajian falsafah pendidikan Islami. Maksud dalam perspektif falsafah pendidikan Islami dalam makalah ini adalah penulis mengkaji empat hal tersebut menurut informasi al-Qur'an, Hadis dan pendapat para ulama. Kajian ini memang menarik, karena falsafah diaplikasikan terhadap ilmu pendidikan. Di sini, falsafah Islam diterapkan dalam merumuskan teori pendidikan, yang dalam konteks ini adalah teori pendidik.

\section{Terminologi Pendidik}

Menurut Al Rasyidin (2018: 133), bahwa dalam perspektif falsafah pendidikan Islami, dikenal beberapa istilah yang merujuk pada makna pendidik, yaitu murabbi, mu'allim, mu'addib, syekh, mursyid, mudarris, dan ustaz.Jika dilacak akar-akar seluruh istilah tersebut, maka akan terlihat bahwa penggunaan istilah tersebut terinspirasi dari al-Qur'an, hadis dan ijtihad ulama. Dua istilah pertama, murabbi dan mu'allim, diambil dari al-Qur'an. Istilah mu'addib diambil dari hadis Nabi, sedangkan istilah syekh dan mursyid diambil dari tradisi tasawuf. Istilah mudarris dan ustaz diambil dari tradisi peradaban Islam, khususnya tradisi Bahasa dan Sastra Arab. Inilah makna bahwa pendidikan Islam bersumber dari al-Qur'an, hadis dan ijtihad ulama sepanjang peradaban Islam, sehingga istilah pendidik pun diambil dari ketiga tradisi tersebut.
Dalam bahasa al-Qur'an, pendidik disebut murabbi dan múalim. Argumennya didasarkan pada surah alFatihah ayat 2 dan surah al-Baqarah ayat 31. Dalam surah al-Fatihah ayat 2 disebutkan bahwa Allah adalah rabb semesta alam. Kata murabbi, merupakan bentuk mashdar dari kata rabba berarti "mengasuh, mendidik dan memelihara." Istilah yang digunakan dalam ayat ini adalah $R a b b$, derivasinya adalah tarbiyah (pengasuh, pendidik dan pemelihara), dan pelakunya adalah murabbi. Karena itu, dalam konteks ayat ini, Allah Swt. berperan sebagai murabbi bagi alam semesta. Karena itu, arti surah al-Fatihah ayat 2 bisa menjadi 'Segala puji bagi Allah, Pemelihara/Pengasuh/Pendidik semesta alam." Sedangkan dalam surah al-Baqarah ayat 31 disebutkan bahwa Allah mengajarkan ('allama) Adam nama-nama segala sesuatu. Istilah yang digunakan dalam ayat ini adalah 'allama, derivasinya adalah ta'lim (pengajaran) dan pelakunya adalah mu'allim. Karena itu, dalam ayat ini, Allah Swt. Adalah Mu'allim bagi Adam as. (Al Rasyidin, 2018: 133-134). Dengan demikian, dalam al-Qur'an, pendidik disebut dengan term murabbi.

Selain kedua istilah di atas, Nabi menggunakan istilah $t a^{\prime} d i b$, penanaman adab, dan pelakunya adalah mu'addib. Istilah ta'dib sebagai istilah untuk merujuk pada makna pendidik dalam Islam didasarkan pada Hadis Nabi, Tuhan telah mendidikku (addabani rabbi) dengan sebaik-baik pendidik (fa ahsana ta'dibi), dan Hadis Nabi lain yaitu jika memelihara seorang anak, maka berikanlah pendidikan yang baik (fa ahsana ta'dibaha). Dengan demikian, dalam hadis Nabi, pendidik juga disebut mu'addib.

Dalam tradisi tasawuf, dikenal istilah syekh dan mursyid yang bermakna guru sufi. Menurut Abubakar Aceh, syekh atau guru sufi bertugas mengawasi para muridnya agar tidak menyimpang dari 
ajaran Islam dan terjerumus dalam dosa dan maksiat. Di sini, syekh atau mursyid menjadi perantara antara murid dengan Allah Swt. Syekh dan mursyid memiliki khalifah yang bertugas membantu syekh untuk membimbing murid pemula (Aceh, t.t.: 79). Dalam konteks ini, ajaran tasawuf memiliki dimensi edukatif, terutama konsep tentang adab murid terhadap syekh atau mursyid (Ja'far: 2015). Dengan demikian, dalam peradaban Islam sebagaimana dalam tradisi tasawuf, guru disebut syekh atau mursyid.

Selain itu, dalam tradisi Islam, mudarris dan ustadz juga dimaknai sebagai pendidik. Al Rasyidin menjelaskan bahwa mudarris berasal dari bahasa Arab, darasa, yadrusu darsan, yang mengandung makna "terhapus, hilang bekasnya, melatih dan mempelajari." Nah, makna mudarris, menurut Al Rasyidin, adalah orang yang berusaha menghilangkan dan memberantas kebodohan, melatih keterampilan dan mengajarkan pengetahuan baru kepada peserta didiknya. Untuk kata ustadz, Al Rasyidin (2018: 135-136) melanjutkan, merujuk kepada seorang guru besar atau profesor, sehingga, seorang pendidik sebagai ustadz harus memiliki kualifikasi profesional dalam menjalankan serangkaian tugasnya.

\section{Hakikat Pendidik}

Sebelumnya telah dijelaskan bahwa dalam konteks falsafah pendidikan Islami, pendidik ideal dalam Islam, atau hakikat pendidik dalam Islam, adalah Allah Swt. dan Nabi dan Rasul. Lalu, menurut Al Rasyidin, ada dua pendidik lainnya yaitu ulama sebagai pewaris para Nabi dan Rasul dan orang tua sebagai pendidik bagi anak-anak mereka (Al Rasyidin, 2018: 136-141).

Hakikat pendidik yang pertama adalah Allah Swt. Pernyataan ini didasarkan kepada Q.S. al-Fatihah ayat 2
(Allah Swt. sebagai Maha Pendidik/Murabbi), Q.S. al-Baqarah ayat 31 (Allah Swt. sebagai Maha Pengajar/Mu'allim) dan hadis Nabi tentang $t a^{\prime}$ dib. Dalam Q.S. al-Fatihah ayat 2, dijelaskan bahwa Allah adalah Rabb bagi alam semesta. Kata Rabb seakar dengan tarbiyah dan dari kata ini muncul kata murabbi, sehingga Q.S. al-Fatihah ayat 2, seperti kata Al Rasyidin, menunjukkan bahwa Allah Swt. adalah Pendidik Yang Agung bagi seluruh kosmos atau alam semesta (Al Rasyidin, 2018: 136). Berdasarkan Q.S. al-Baqarah ayat 31, Allah Swt. mengajarkan ('allama) Adam, sehingga Allah Swt. merupakan Mu'allim bagi Adam yang menjadi muta'allim dalam konteks ini. Dalam Q.S. al-'Alaq ayat 5, disebutkan juga bahwa Allah mengajarkan ('allama) manusia tentang banyak hal ('allama al-insan ma lam ya'lam). Dua ayat ini, kata Al Rasyidin, menunjukkan bahwa Allah Swt. merupakan Mu'allim bagi para Nabi dan manusia seluruhnya (Al Rasyidin, 2018: 137). Dalam Hadis riwayat Ibn Hibban, dijelaskan bahwa Allah Swt. merupakan Mu'addib bagi Nabi Muhammad Saw. ( أدَّبنَى

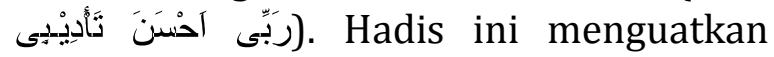
bahwa Allah Swt. adalah Maha Pendidik, Murabbi, Mu'allim, dan Mu'addib.

Hakikat pendidik yang kedua adalah para Nabi dan Rasul. Dasar pendapat ini adalah Q.S. al-Baqarah ayat 151. Dalam ayat ini ditegaskan bahwa Allah Swt. mengurus para Rasul untuk membacakan ayat-ayat Allah Swt. (yatlu 'alaikum 产ătina), menyucikan jiwa manusia (yuzakkikum) dan mengajarkan manusia Kitab, Hikmah dan Ilmu (yu'allimukum al-kitab, al-hikmah dan ma lam takūnù ta'lamün). Beberapa ayat lain menunjukkan bahwa para Nabi dan Rasul bertugas membacakan ayat-ayat Allah Swt., menyucikan jiwa manusia dan mengajarkan manusia Kitab, Hikmah dan Ilmu seperti terlihat dalam Q.S. Ali 'Imran 
ayat 164 dan Q.S. al-Jumu'ah ayat 2 (Al Rasyidin, 2018: 137-138). Para Nabi dan Rasul bahkan menjadi teladan bagi seluruh manusia (uswah al-hasanah) sebagaimana disebutkan dalam Q.S. alAhzab ayat 21. Karenanya, para Nabi dan Rasul menjadi contoh bagi manusia. Jelas bahwa para Nabi dan Rasul merupakan murabbi, mu'allim dan mu'addib bagi manusia, dan kedudukan mereka diperoleh berkat kesempurnaan mereka sebagai manusia. Kesempurnaan Para Nabi dan Rasul sebagai manusia dan kelak menjadi pendidik manusia adalah karena mereka didik langsung oleh Maha Pendidik, yakni Allah Swt.

Hakikat pendidik yang ketiga adalah para ulama yang merupakan pewaris para Nabi. Di antara dalil bagi pernyataan ini adalah Q.S. al-Fāthir ayat 28. Istilah ulama disebut al-Qur'an sebagai orang yang sangat takut (khasyyah) kepada Allah Swt. Dalam Hadis Nabi yang terdapat dalam Sunan Abi Dawud, disebutkan bahwa ulama adalah pewaris para Nabi (al-'ulama' waratsat al-anbiya'). Selain kata ulama, alQur'an menyebutkan beberapa istilah yang identik dengan ulama, yaitu al'alimun (orang-orang berilmu), ulu alalbab (orang-orang berakal), ulu al-nuha (orang-orang berakal), ulu al-ilm (orangorang berilmu), dan utu al-ilm (orang yang diberi ilmu). Menurut Ali Masykur Musa, ada empat tugas ulama yang dalam hadis juga disebut hukama' dan fuqaha', yakni tabligh (menyampaikan pesanpesan agama, Q.S. al-Nisa ayat 63), tahkim (memutus perkara dengan bijaksana, Q.S. al-Baqarah ayat 213), tibyan (menjelaskan masalah agama berdasarkan kitab suci, Q.S. al-Nahl ayat 44), dan uswah hasanah (memberikan keteladanan yang baik, Q.S. al-Ahzab ayat 21) (Musa, 2014: 226).

Hakikat pendidik yang keempat adalah orang tua. Pendapat ini didasarkan kepada Q.S. al-Isra' ayat 24 dan Q.S.
Luqman ayat 12-19. Q.S. al-Isra' ayat 24 menyiratkan bahwa orang tua bertugas mendidik, memelihara dan mengasuh

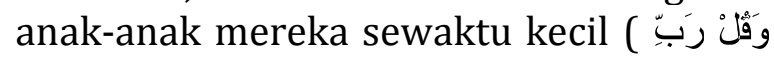
(ارْخَمْهُمَا كَمَا ربَيَيَنِي صَغِيرًا ayat 12-19, dijelaskan bahwa Luqman adalah orang yang mendapatkan hikmah dari Allah Swt., dan kemudian Luqman mendidik anaknya dengan mengajarkan ketauhidan dan menolak kemusyrikan, berbuat baik kepada orang tua, salat, amar makruf nahi mungkar, sabar, sederhana, dan melunakkan suara. Dengan demikian, al-Qur'an menegaskan bahwa Allah Swt. mengamanahkan orang tua untuk mendidik anak-anak mereka.

\section{Kepribadian dan Tugas Pendidik}

Sebagaimana telah dijelaskan di atas, bahwa hakikat pendidik adalah Allah Swt., para Nabi dan Rasul dan ulama. Mereka adalah murabbi, mu'allim dan mu'addib. Sebagai pendidik, Allah Swt. dan para Nabi dan Rasul memiliki kepribadian yang harus ditiru oleh para pendidik Muslim. Dalam Shahih ibn Hibban, Nabi menjelaskan bahwa Allah Swt. memiliki 99 nama, dalam bahasa AlQur'an disebut al-asma' al-husna (Q.S. alHasyr ayat 24). Para sufi, menurut Sachiko Murata, menjelaskan bahwa nama-nama Allah Swt. terbagi menjadi dua, yaitu nama-nama keindahan (jamaliyah) dan nama-nama keagungan (jalaliyah). Jadi, nama-nama Allah Swt. memiliki dua dimensi, nama-nama keindahan (jamaliyah) dan nama-nama keagungan (jalaliyah). Manusia sempurna (al-insān al-kämil) adalah manusia yang dapat menyatukan kedua dimensi namanama Allah Swt. tersebut (Murata, 2004: 103). Dalam mendidik alam dan para Nabi dan Rasul, Allah Swt. menampilkan diriNya sebagai Maha Pendidik yang memiliki kepribadian yang baik sebagaimana termanifestasi dalam nama-nama-Nya. 
Dalam konteks inilah, menurut $\mathrm{Al}$ Rasyidin, para pendidik Muslim harus meneladani karakter Allah Swt. yang tersimpul dalam al-asma' al-husna (Al Rasyidin, 2018: 144). M. Quraish Shihab (2018: 512) menguatkan bahwa seorang Muslim harus berakhlak dengan akhlak Allah Swt. sesuai dengan kemampuannya sebagai makhluk, dan ini merupakan perintah Nabi kepada umatnya. Karenanya, pendidik Muslim harus bisa mengaktualisasikan al-asma' al-husna dalam kehidupannya sebagai pendidik. Sekadar contoh, seorang pendidik Muslim harus memiliki sifat seperti pengasih, penyayang, penyabar, adil, bijaksana dan pemaaf.

Nabi dan Rasul sebagai murabbi, mu'allim dan mu'addib menampilkan diri mereka sebagai manusia sempurna yang memiliki akhlak yang agung (khuluq 'azhim). Dalam kajian teologi, wujud iman kepada para Nabi dan Rasul adalah meyakini bahwa para Nabi dan Rasul memiliki sifat-sifat istimewa, dan terpeliharan dari sifat-sifat tercela. Menurut M. Taib, di antara sifat para Nabi dan Rasul yang terpenting adalah siddik, amanah, tabligh dan fathanah (Muin, 1986: 151). Dalam kitab al-Jawahir alKalämiyah, makna siddik adalah para Nabi membawa ajaran yang benar, sehingga tidak mungkin mereka berbohong. Para Nabi juga bersifat amanah, maksudnya adalah bahwa mereka mereka terpelihara dari segala hal yang tidak diridai Allah Swt. Para Nabi juga bersifat tabligh, artinya mereka menyampaikan semua perintah Allah Swt., dan menjelaskannya dengan penjelasan yang jernih. Para Nabi juga bersifat fathanah, artinya mereka merupakan manusia paling sempurna dari aspek kecerdasan dan pemahaman terhadap kehidupan. Karena itu, para Nabi dan Rasul tidak memiliki sifat alkazib (dusta), al-ishyan (durhaka), alkitman (menyembunyikan) dan al-ghaflah (pelupa) (al-Jazairi, 2000: 42-43). Dalam konteks ini, para pendidik Muslim harus meniru sifat-sifat mulia para Nabi dan Rasul sebagai bentuk ketaatan kepada mereka (Bandingkan dengan Ja'far dalam Asrul dan Ja'far, 2016: 279-296).

Secara khusus, Nabi Muhammad Saw. sebagai Nabi dan Rasul memiliki sifat-sifat yang luhur dan agung. Allah Swt., menurut Quraish Shihab, (2018: 5758) memerintahkan Nabi Muhammad Saw. untuk meneladani sifat-sifat terpuji para Nabi dan Rasul sebagaimana dijelaskan dalam Q.S. al-An'am ayat 90 . Shihab menyebutkan bahwa Nabi Nuh memiliki sifat gigih dan tabah, Nabi Ibrahim memiliki sifat pemurah dan tekun beribadah, Nabi Daud memiliki sifat syukur, Nabi Yahya dan Nabi 'Isa memiliki sifat zuhud, Nabi Yusuf memiliki sifat gagah dan sabar, Nabi Musa memiliki sifat berani dan tegas, sedangkan Nabi Harun memiliki sifat yang lembut (Shihab, 2018: 68). Sebagaimana Nabi Muhammad Saw. diperintahkan untuk meneladani sifatsifat terpuji para Nabi dan Rasul, para pendidik Muslim juga harus meneladani sifat-sifat istimewa dan terpuji yang ditampilkan orang para Nabi dan Rasul yang sukses memainkan peran sebagai murabbi, mu'allim dan mu'addib bagi umatnya masing-masing.

Sedangkan tugas pendidik dalam perspektif pendidikan Islami mengacu kepada tiga hal berikut. (1) pendidik Muslim bertugas melanjutkan tugas-tugas para Nabi dan Rasul sebagaimana dijelaskan dalam Q.S. al-Baqarah ayat 151, Q.S. Ali 'Imran ayat 164 dan Q.S. alJumu'ah ayat 2 . Ketiga ayat ini menjelaskan bahwa Allah sebagai Maha Pendidik mengurus para Nabi dan Rasul untuk tiga tugas. Pertama, membacakan ayat-ayat Allah kepada manusia. Kedua, mengajarkan hikmah kepada manusia. Ketiga, mengajarkan ilmu kepada manusia. Karena itu, tugas pendidik 
Muslim adalah melanjutkan tugas-tugas para Nabi dan Rasul yaitu mendidik peserta didik dalam hal ayat-ayat Allah, hikmah dan ilmu. (2) pendidik Muslim bertugas mengantarkan peserta didik untuk mencapai tujuan hidupnya yaitu bersyahadah kepada Allah Swt. (Q.S. alA'raf ayat 172), menjalankan fungsinya sebagai hamba Allah yang senantiasa beribadah kepada-Nya (Q.S. al-Dzariyat 53), dan mengemban tugasnya sebagai khalifah Allah Swt. di bumi (Q.S. alBaqarah ayat 30) (Al Rasyidin, 2018: 142143). (3) pendidik bertugas untuk meneruskan tugas para ulama sebagai penyampai pesan-pesan agama kepada peserta didiknya, pemutus masalah peserta didiknya secara bijaksana, penjelas masalah agama kepada peserta didiknya berdasarkan kitab suci, dan pemberi teladan yang baik kepada peserta didiknya.

\section{PENUTUP}

Berdasarkan kajian di atas, dapat disimpulkan bahwa pendidik ideal adalah Allah Swt., pada Nabi dan Rasul, dan para ulama. Tugas pendidik Muslim, dengan demikian, adalah meniru para pendidik ideal tersebut, terutama memiliki dan menerapkan kepribadian para pendidik ideal tersebut. Para pendidik Muslim, lebih lanjut, harus berakhlak dengan akhlak Allah, sehingga pendidik Muslim memiliki dan menampilkan sifat jamaliyah dan sifat jalaliyah Allah Swt. sebagai Maha Pendidik. Demikian juga, para pendidik Muslim harus meneladani sifat-sifat para Nabi dan Rasul. Secara teologis, ada empat sifat wajib Nabi: siddik, amanah, tabligh dan fathanah, serta empat sifat mustahil: kazib, khiyanat, kitman dan jahil atau ghaflah (pelupa). Karenanya, pendidik Muslim haruslah menjadi sosok yang siddiq, amanah, tabligh dan fathanah. Kemudian, para pendidik juga harus meneladani kepribadian para ulama di dunia Muslim. Sekadar contoh, Imam Syafi'i selalu menjaga wuduknya, sehingga pendiri mazhab Syafi'iyah ini selalu dalam keadaan suci dalam menjalankan aktivitas sehari-harinya. Karena itu pula, para pendidik juga harus suci dengan menjaga wuduk. Dengan meneladani kepribadian Allah Swt., Nabi dan Rasul dan ulama, para pendidik Muslim akan menjadi pendidik ideal dalam Islam.[]

\section{DAFTAR RUJUKAN}

Aceh, Abubakar. Pengantar Ilmu Tarekat: Kajian Historis tentang Mistik. Solo: Ramadhani, t.t.

Al-Jazairi, Thahir ibn Shaleh. Jawahir Kalamiyah: Ilmu Tauhid, terj. Ja'far Amir. Pekalongan: Raja Murah, 2000.

Al-Syaibani, Omar Muhammad al-Toumy. Falsafah Pendidikan Islam, terjemahan Hasan Langgulung. Jakarta: Bulan Bintang, 1979.

Arbi, Sutan Zanti. Pengantar Kepada Filsafat Pendidikan. Jakarta: Depdiknas, 1988.

Asrul dan Ja'far. "Pengantar Editor," dalam Asrul Daulay \& Ja'far (ed.), Falsafah Pendidikan Islami: Menguak Nilai-nilai Pendidikan dalam Tradisi Islam. Medan: Perdana Publishing, 2016.

Barnadib, Imam. Filsafat Pendidikan. Yogyakarta: IKIP Yogyakarta, 1984.

Dewey, John. Democracy and Education. New York: The Free Press, 1944.

Gibbs, P., dan E. Blakely. Gatekeeping in BSW Programs. New York: Columbia University Press, 2000.

Huges, Thomas Patricks. Dictionary of Islam. New Delhi: Adam Publisher \& Distributors, 2002.

Ja'far, Ja'far. "Tarekat dan Gerakan Sosial Keagamaan Shaykh Hasan 
Maksum." Teosofi: Jurnal Tasawuf dan Pemikiran Islam 5.2 (2015): 269-293.

Ja'far, Ja'far. "Falsafah Pendidikan Al Jam'iyatul Washliyah," dalam Asrul dan Ja'far. Falsafah Pendidikan Islami. Medan: Perdana Publishing, 2016.

Ja'far, Ja'far. “Peran Al Jam'iyatul Washliyah Dalam Merevitalisasi Madhhab Shafi'i Di Era Kontemporer." Justicia Islamica: Jurnal Kajian Hukum dan Sosial 13.1 (2016): 1-29.

Jafar, Jafar. "Al Jam'iyatul Washliyah dan Problem Kepemimpinan Non Muslim dan Perempuan." Ahkam: Jurnal Ilmu Syariah 17.2 (2017). 413-434.

Muin, M. Taib Thahir Abd. Ilmu Kalam. Jakarta: Widjaya, 1986.

Murata, Sachiko. The Tao of Islam: Kitab Rujukan tentang Relasi Gender dalam Kosmologi dan Teologi Islam. Bandung: Mizan, 2004.

Musa, Ali Masykur. Membumikan Islam Nusantara: Respons Islam terhadap Isu-isu Aktual. Jakarta: Serambi, 2014.

Netton, Ian Richard. A Popular Dictionary of Islam. USA: Curzon Press, 1997.

Rasyidin, Al. Falsafah Pendidikan Islami: Membangun Kerangka Ontologi, Epistemologi dan Aksiologi Praktik Pendidikan Islami. Bandung: Citapustaka media, 2018.

Shihab, M. Quraish. Wawasan Al-Qur'an. Bandung: Mizan, 2018.

Siddik, Dja'far. Konsep Dasar Ilmu Pendidikan Islam. Bandung: Citapustaka Media, 2010.

Syafaruddin dan Al Rasyidin. Filsafat Pendidikan Islam. Medan: IAIN Press, 2001.

Syafaruddin, et al.Ilmu Pendidikan Islam: Melejitkan Potensi Budaya Umat. Jakarta: Hijri, 2014. 